\title{
Technical Note: Updating procedure for flood forecasting with conceptual HBV-type models
}

\author{
Th. Wöhling ${ }^{1}$, F. Lennartz ${ }^{2}$, and M. Zappa ${ }^{3}$ \\ ${ }^{1}$ Lincoln Environmental., Ruakura Research Centre, Private Bag 3062, Hamilton, New Zealand \\ ${ }^{2}$ Dresden University of Technology, Würzburger Str. 46, D-01187 Dresden, Germany \\ ${ }^{3}$ Swiss Federal Institute for Forest, Snow and Landscape Research, Zürcherstrasse 111, CH-8903 Birmensdorf, Switzerland
}

Received: 27 January 2006 - Published in Hydrol. Earth Syst. Sci. Discuss.: 7 July 2006

Revised: 4 September 2006 - Accepted: 17 October 2006 - Published: 20 October 2006

\begin{abstract}
Flood forecasting is of increasing importance as it comes to an increasing variability in global and local climates. But rainfall-runoff models are far from being perfect. In order to achieve a better prediction for emerging flood events, the model outputs have to be continuously updated. This contribution introduces a rather simple, yet effective updating procedure for the conceptual semi-distributed rainfallrunoff model PREVAH, whose runoff generation module relies on similar algorithms as the HBV-Model. The current conditions of the system, i.e. the contents of the upper soil reservoirs, are updated by the proposed method. The testing of the updating procedure on data from two mountainous catchments in Switzerland reveals a significant increase in prediction accuracy with regards to peak flow.
\end{abstract}

\section{Introduction}

Flood forecasting has been a key issue in hydrology during the past and gains even more importance due to the current development of increasing climate variability. This issue still remains an unsolved problem in operational hydrology (Garrote and Bras, 1995). A great number of conceptual rainfallrunoff models have been developed but the accuracy of predicted runoff is often low. Therefore, the current model output is continuously updated to represent the current situation in the catchment.

Various updating procedures have been published (O'Connell and Clarke, 1981; WMO, 1992; Refsgaard, 1997) which are, however, mostly not suitable for short forecast periods and a steep flood hydrograph characteristic which is typical for small, quick reacting mountainous catchments. In such catchments it is the primary goal to extend the forecast lead time. This requires procedures that

Correspondence to: Th. Wöhling

(woehling@lvlham.lincoln.ac.nz) update the state variables that govern the runoff generation process of the used rainfall runoff model. Classical updating procedures - e.g. Auto Regression Moving Average approaches (Lettenmaier, 1993; Dyck and Peschke, 1995) - are focussed on the river flow itself which leads to a significant loss of forecast lead time in small, quick reacting catchments. More sophisticated procedures which, for example, are using Kalman filtering (Kalman, 1960) are mathematically too complex to be easily accommodated by the highly non-linear models (Yang and Michelle, 2001). Therefore, we intended to develop a simple but effective updating procedure that allows for the updating of sensitive state variables that control the runoff generation approach of HBV-type conceptual rainfall runoff models.

\section{Methods}

The proposed updating method is a tailor-made algorithm for the spatially semi-distributed Precipitation-Runoff$E$ vapotranspiration- $H$ RU Model PREVAH (Gurtz et al., 1999). The spatial discretization of PREVAH relies on the aggregation of gridded physiogeographical information (gridded maps of elevation, land use, land cover and soil properties) into hydrologic response units HRUs. HRUs are clusters representing areas of the basin where similar hydrological behaviour is expected (Zappa, 2003). Hydrological similarity has been identified according to the elevation, land use, exposition and soil depth of the grid cells (Gurtz et al., 1999). Hydrological similarity in glaciated parts of the basins is accounted by defining the glacier equilibrium line altitude (Klok et al., 2001). The module for soil water storage and depletion by evapotranspiration relies on the HBV-model and the Penman-Monteith equation (see details in Gurtz et al., 1999 and Zappa and Gurtz 2003). Snow and glacier melt are calculated using a modified temperature-index approach, including potential direct clear sky solar radiation

Published by Copernicus GmbH on behalf of the European Geosciences Union. 
Table 1. Model calibration and verification. NSE is the agreement after Nash and Sutcliffe (1970). LOG(NSE) is the logarithmic formulation of NSE (Zappa et al., 2003). VOL is error in discharge volumes between simulation and observation.

\begin{tabular}{lcccccc}
\hline Basin & Run & Period & NSE & LOG(NSE) & VOL $^{1}$ & EVENTS $^{2}$ \\
\hline Verzasca & Calibration & $1991-1996$ & 0.826 & 0.875 & 0.3 & 14 \\
Verzasca & Verification & $1997-2004$ & 0.829 & 0.895 & $-0.6 \%$ & 14 \\
Linth & Calibration & $1991-1995$ & 0.655 & 0.640 & $-1.6 \%$ & 8 \\
Linth & Verification & $1996-2003$ & 0.654 & 0.629 & $-3.1 \%$ & 18 \\
\hline
\end{tabular}

${ }^{1}$ Values below 0 indicate that the model underestimate the observed discharge.

${ }^{2}$ For each basin the total of events is equal to the double of the considered years: the top 28 events between 1991 and 2004 for the Verzasca basins and the top 26 events between 1991 and 2003 for the Linth basin. Two events are considered as independent if there are more than $72 \mathrm{~h}$ between the peaks.

(Hock, 1999; Zappa et al., 2003). The runoff generation module uses concepts from the well established HBV-model (Bergström, 1976; Lindström et al., 1997), adapted to a spatially distributed application (Gurtz et al., 2003). A previous study by Zappa (2003) revealed that the upper runoff storage $S U Z$ is the most sensitive state variable with regards to calculated peak runoff. The land surface runoff, the interflow, and the percolation to the groundwater storage are generated in $S U Z$. Therefore $S U Z$ is updated in the proposed procedure.

In this study we apply PREVAH to two Swiss basins: Verzasca $\left(186 \mathrm{~km}^{2}, 523 \mathrm{HRUs}\right)$ and Linth $\left(600 \mathrm{~km}^{2}, 2490\right.$ HRUs). The Vezasca basin is located in the southern part of Switzerland and poorly affected by human activities. Its elevation range is $490-2870 \mathrm{~m}$ a.s.l. Forests (30\%), shrub $(25 \%)$, rocks $(20 \%)$ and alpine pastures $(20 \%)$ are the predominant land cover classes. Soils are rather shallow (generally $<30 \mathrm{~cm}$ ) and the plant available filed capacity is below $5 \%$ volume. The discharge regime is governed by snowmelt in spring and early summer and by heavy rainfall events in fall.

The Linth basin is located in central Switzerland. The discharge regime up to the gauge in Mollis is heavily affected by hydropower. Water stored in two big reservoirs during spring and summer is released for production of peak electricity. Thus we can observe a distinct daily and weekly cycle in the hydrograph. The basin shows a range of elevation between 435 and $3610 \mathrm{~m}$ a.s.1. $20 \%$ of the basin are covered by forests. The portion of rocks and bare soil areas is $34 \%$. Large parts of the watershed are used for pasture $(31 \%)$. In the highest regions there are some small glaciers which make about $4 \%$ of the total basin area. The soils are well developed in the valley (with depths $>1.5 \mathrm{~m}$ and large plant available field capacity). In contrast, the surrounding hills are characterized by shallow soils and a reduced plant available field capacity.

The hourly data of the required meteorological variables was obtained from automatic stations of MeteoSwiss (AMS). Additional local information on precipitation was obtained from a dense network of daily raingauges. The spatial interpolation relies on interpolation schemes similar to that of
Garen and Marks (2001) and Klok et al. (2001). The interpolation algorithms adopted here is an elevation de-trended inverse distance weighting. For the Verzasca basin we adopted 4 AMS and six raingauges. For the Linth we used 5 AMS and 23 raingauges. The choice of the stations considered the need for stations at high elevations in order to better represent the temperature gradients. For operational application of the Linth (2005 event) only AMS were available.

PREVAH's calibration procedure relies on the monitored maximisation of an acceptability score based on nine different objective functions derived by the comparison between the observed and the simulated hourly discharge (Sonderegger, 2004; Verbunt et al., 2006). The functions test the overall agreement between observation and simulation and combine equations from Nash and Sutcliffe (1970), Legates and McCabe (1999) and Zappa et al. (2003). Table 1 reports the results of the model calibration and verification for both basins. The perturbation of the observed hydrograph due to hydropower management in the Linth basins is not considered by the model and therefore partly responsible for the obtained low values for the Nash and Sutcliffe efficiency.

\section{Updating procedure}

Model predictions of runoff from a catchment $\left(Q_{s}\right)$ often differ from the observations $\left(Q_{m}\right)$. A simple but effective method is introduced to adapt the model state to the observations from the natural system: If the difference between the simulated (PREVAH) runoff and the measured runoff, $\Delta Q=Q_{s}-Q_{m}$, exceeds a certain tolerance threshold $\varepsilon$, the content of the upper soil reservoir SUZ is updated by a factor $F$. This change in reservoir content due to updating is neglected in the volume balance computations. An iterative solution is required to determine the value of $F$ for the minimization of $\Delta Q$.

The spatial discretization of PREVAH relies on the concept of hydrological response units (Gurtz et al., 1999). The current state of the variables is calculated for each HRU in the catchment. But spatially information of the current state 
of the catchment is usually not available. Therefore the state variable $S U Z$ is updated for all HRUs in equal measure.

The updating algorithm is designed for hourly time steps. But in this tailor-made application, we can not just use one updating factor which is calculated at the end of each hourly time step. The reason being is the development history of PREVAH. The original model (e.g. in Gurtz et al., 1997) was developed by coupling different modules at daily time step. For better representation of the hydrological response from mountainous basins the computation of snow cover dynamics and runoff generation was then extended to the hourly time step (e.g., Gurtz et al., 2003 and Zappa et al., 2003). Evapotranspiration is still based on algorithms requiring daily meteorological input and is computed prior to the runoff generation in order to update the soil moisture storage (Gurtz et al., 1999). Thus, all hourly data has to be aggregated to the daily time step before running the runoff module. This requires reading all input data for one day at the beginning of a new day. Therefore PREVAH has a time loop structure, which may seem to be not straight forward:

\section{[Years [Months [Days [HRUs [Hours] ]] ]]}

Due to this structure, a stepwise simultaneous assessment (updating) of hourly state variables of the catchment (e.g. soil moisture storage, snow water equivalent, interception storage, groundwater storage) is not possible. Currently, the state of the entire catchment is only accessible at daily intervals. But these are far too much for flood forecasting in small, flash flood exposed catchments. The way out of the dilemma is to use a vector of updating factors $F(i=1 . .24)$, where $i$ denotes the count of the hours of a simulation day. At the beginning of each day, an initial run without updating $(F[1 . .24]=1)$ is conducted. The model results are evaluated at daily intervals. If $\Delta Q(i=1)$ exceeds the tolerance criterion $\varepsilon$, the factor $F(i=1)$ is calculated by Eq. (1) and the calculations of the day are repeated (Fig. 1). Now the state of $S U Z$ is multiplied by $F(1)$ at the time $t=1 \mathrm{~h}$ within the loop of the HRUs. The calculations proceed as by the original PREVAH code for all coming hours of the simulation day. At the end of the day, $\Delta Q(i=1)$ is evaluated again. The procedure is repeated until $\Delta Q(i)<\varepsilon$. Then calculations proceed to the next hour where this condition fails. The $F(i)$-values of preceding time steps are stored until the simulation of the day is completed $(i=24)$. Then the calculations proceed to the next simulation day (Fig. 1).

We applied the secant method for determining iteratively the factor $F(i)$ :

$$
\begin{array}{r}
F(i)^{j+1}=F(i)^{j}-\left[Q_{s}^{j}(i)-Q_{m}(i)\right] \\
\frac{\left[F(i)^{j}-F(i)^{j-1}\right]}{\left[Q_{s}^{j}(i)-Q_{m}(i)\right]-\left[Q_{s}^{j-1}(i)-Q_{m}(i)\right]}
\end{array}
$$

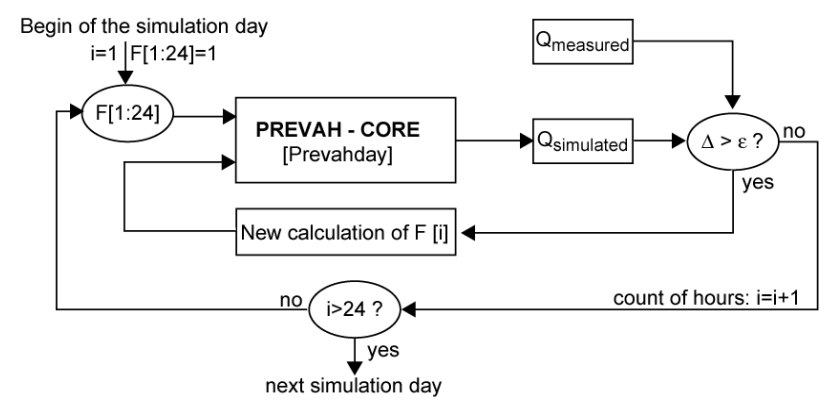

Fig. 1. Principles of the PREVAH updating procedure.

where, $i=[1 . .24]$ is the count of hours during a simulation day, $j=[1 \ldots 12]$ is the iteration count of the updating loop. Convergence is usually achieved quickly within 3 or 4 iterations.

For certain (theoretical) model states, the updating of $S U Z$ may not succeed to minimize the objective function by the required precision criteria. For example: if simulated runoff is over-predicted and $S U Z$ is already empty, the content of this reservoir can not be further reduced. The best solution achieved by a maximum of 12 iterations is used in such a case and the updating proceeds to the next time step. As a side effect, this approach, therefore, also damps the effect of measurement errors (outliers) since the reservoir content can only be updated within its physical limits.

The date and hour of a proposed updating are user defined by the help of a control file which contains a record of the date and hour, the observed discharge and the control integer $U$ which indicates either updating $(U=1)$ or no updating $(U=0)$. The precision criteria $\varepsilon$ is also user defined. It is the second constraint for updating: model calculations proceed without updating if $U(i)=1$ but $\Delta Q(i) \geq \varepsilon$ applies.

\section{Results and discussion}

We tested the updating procedure on two well observed mountainous catchments in Switzerland. The model was first run on continuous basis. The model conditions can stored at the end of each day. We exploited this option to make event based runs for the presented floods and quantify the difference with respect to the continuous simulation. Model parameterization, calibration and verification following the procedure presented in Zappa et al. (2003). Figure 2 shows the analysis of the 1993 flood for the $186 \mathrm{~km}^{2}$ Verzasca catchment. The simulation of the event at 02/10/1993, with peak flow at 02:00 PM is updated by the proposed procedure $(U=1)$ up to the time at 02/10/1993, 07:00 AM. After that time, PREVAH predicts the discharge $(U=0)$. The updating precision criterion was set to 5 percent $(\varepsilon=0.05)$. The prediction of the peak flow by the updated simulation run is 


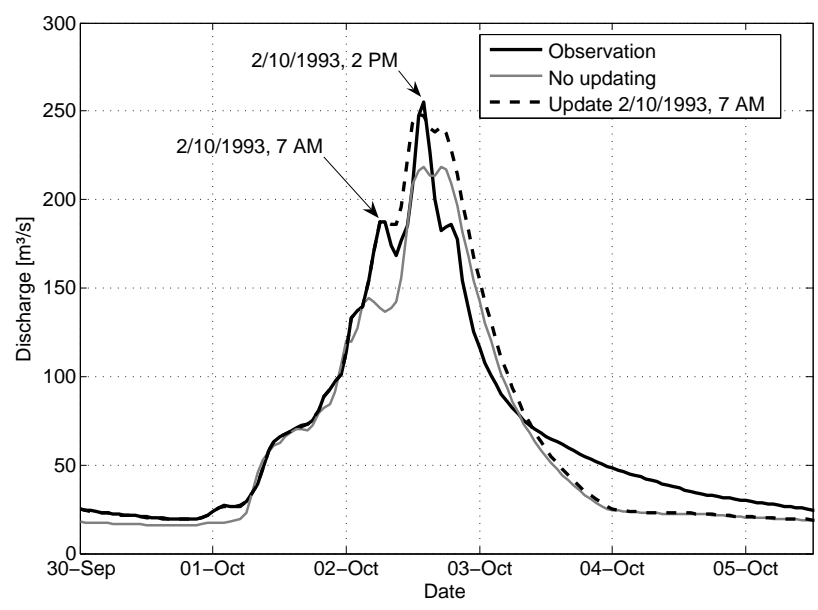

Fig. 2. Comparison of measured and simulated discharge (Verzasca catchment): 1) the calibrated PREVAH run and 2) the same run with updating until 02/10/1993, 07:00 AM.

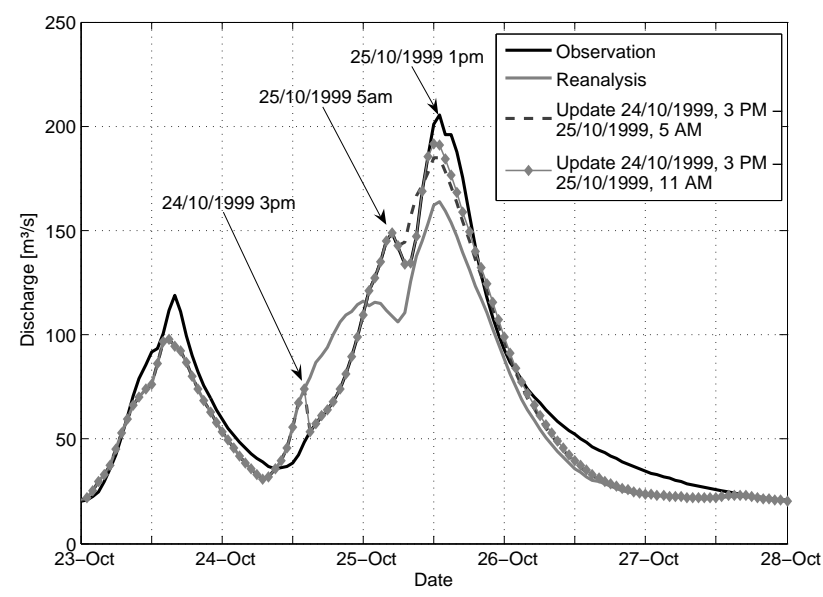

Fig. 3. Comparison of measured discharge and discharge reanalysis with PREVAH for the Verzasca basin. The peak flow was on 25/10/1999 at 01:00 PM.

much better (95.3\% of peak flow) as compared to the peak flow prediction by the calibrated run ( $84.3 \%$ of peak flow).

In a similar event in October 1999 (Fig. 3) the calibrated model run provides a rather large overestimation of discharge the day before the flood peak, while the peak itself is underestimated (79.8\% of peak flow). By updating the model up to $6 \mathrm{~h}$ before the peak, an improvement is obtained (simulated peak $89.8 \%$ of observed peak flow). By continuing the update up to $2 \mathrm{~h}$ before the event a further small improvement is achieved (93.1\% of peak flow).

Figure 4 shows the reanalysis of the 2002 flood for the $600 \mathrm{~km}^{2}$ Linth basin (gauge Mollis) in the county of Glarus. The natural discharge in this basin is rather perturbed by hydropower management. PREVAH has been applied in reanalysis mode for the hindcast of this event, where the reservoir

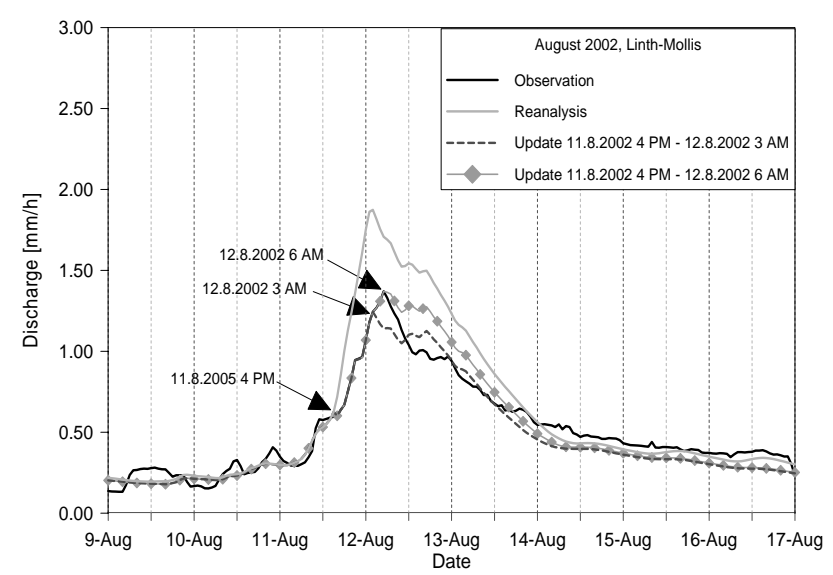

Fig. 4. Comparison of measured discharge and discharge nowcasting with PREVAH for the perturbed Linth basin.

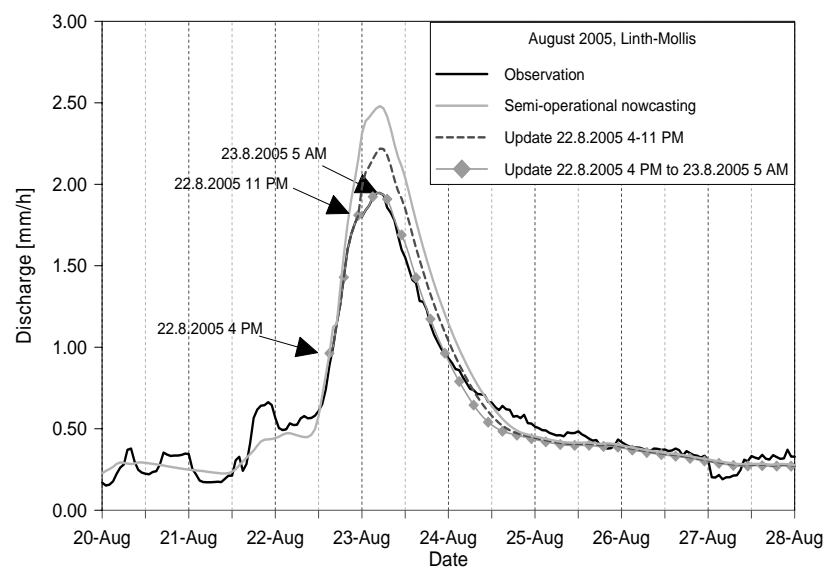

Fig. 5. Comparison of measured discharge and discharge reanalysis with PREVAH for the perturbed Linth basin.

retained a large amount of water. The application of the calibrated model shows a large overestimation of the flood peak. If the updating is applied up to three hours before the peak at 12/08/2002, 06:00 AM, then the actual peak is slightly underestimated. After the peak the hindcast simulation agrees well with the observation. If the updating procedure is adopted up to the time of peak flow), then a slight overestimation is observed for the 48 hours following the event.

Figure 5 shows a first semi-operational application of the updating procedure. PREVAH is implemented since July 2005 for runoff-nowcasting for the Linth basin. In August 2005 a severe flood event occurred in Switzerland. In the Linth basin the river reached a peak discharge of $1.95 \mathrm{~mm}$ per hour at 05:00 of 23 August. Since the operating companies do no provide so far real-time data on the water storage and release, the hydrological model, as currently implemented for discharge nowcasting, fails to estimate the discharge peak. Approximately $20 \%$ of peak flow was cut-off through water storage within reservoirs. 
In the event analysis we applied the updating routine as soon as the flow exceeds $1 \mathrm{~mm}$ per hour in the ascending phase of the flood peak. If we adopt the updating procedure up to $6 \mathrm{~h}$ before the peak, the error in peak estimation is reduced by $50 \%$. If the procedure is adopted until the time of peak flow, then very good conditions for the following hours, when the water level sinks, are obtained.

In such a case the updating procedure provide less support for improvement in flood control, but demonstrates its capability of improving the initial conditions of the model at every desired time step during a flood event. This capability of the procedure will find its best application once the simulations will be coupled with operational forecasts from numerical weather models.

This short technical note provides an effort towards reducing uncertainty in initial conditions for operational discharge simulation with hydrological models relying on HBV-type runoff generation module (Lindstöm et al., 1997; Zhang and Lindström, 1997; Uhlenbrook and Leibundgut, 2002; Gurtz et al., 1999). The procedure worked well in the application range of PREVAH (basin size 50 to $2000 \mathrm{~km}^{2}$ and basin response times $>1$ to $2 \mathrm{~h}$ ). The procedure itself should work also for other dimensions and shorter corrivation times. In such case other models are required.

The procedure is particularly efficient if the model underestimate runoff generation at the beginning of a flood event. In operational use we suggest to adopt the procedure automatically at every time step as soon as the observed discharge exceeds a basin specific critical level, in order to provide valid starting values for extrapolation for the next hours by mean precipitation and temperature forecasts.

Acknowledgements. The work of Th. Wöhling and F. Lennartz on the updating procedure was sponsored by the European Community whereas the work of M. Zappa on runoff nowcasting within the Linth basin has been financed by the Prevention Foundation of the Cantonal Public Building Insurance Companies (Switzerland). MeteoSwiss is acknowledged for providing the meteorological data.

Edited by: A. Barros

\section{References}

Bergström, S.: Development and Application of a Conceptual Runoff Model for Scandinavian Catchments, Bulletin Series A, No. 52, University of Lund, 1976.

Dyck, S. and Peschke, G.: Grundlagen der Hydrologie (in German), 3rd Ed., Verlag fuer Bauwesen, Berlin, Germany, ISBN:3345005867, 1995.

Garen, D. and Marks, D.: Spatial fields of meteorological input data including forest canopy corrections for an energy budget snow simulation model, in: Soil-Vegetation-Atmosphere Transfer Schemes and Large Scale Hydrological Models, edited by: Dolman, A. J., Hall, A. J., Kavvas, M. L., Oki, T., and Pomeroy, J. W., IAHS Publication No. 270, 349-353, 2001.
Garrote, I. and Bras, R. J.: A distributed model for real-time flood forcasting using digital elevation models, J. Hydrol., 167, 279306, 1995.

Gurtz, J., Baltensweiler, A., and Lang, H.: Spatially distributed hydrotope-based modelling of evapotranspiration and runoff in mountainous basins, Hydrol. Processes, 13, 2751-2768, 1999.

Gurtz, J., Zappa, M., Jasper, K., Lang, H., Verbunt, M., Badoux, A., and Vitvar, T.: A comparative study in modelling runoff and its components in two mountainous catchments, Hydrol. Processes, 17, 297-311, 2003.

Hock, R. : Distributed temperature-index ice- and snowmelt model including potential direct solar radiation, J. Glaciol., 45, 101111, 1999.

Kalman, R. E.: A new approach to linear filtering and prediction problems, J. Basic Engineering, 82 (Series D), ISSN 0021-9223, pp. 35-45, 1960.

Klok, E. J., Jasper, K., Roelofsma, K. P., Badoux, A., and Gurtz, J.: Distributed hydrological modelling of a glaciated Alpine river basin, Hydrol. Sci. J., 46, 553-570, 2001.

Legates, D. R. and McCabe, G. J.: Evaluating the use of "Goodnessof-Fit" measures in hydrologic and hydroclimatic model validation, Water Resour. Res., 35, 233-241, 1999.

Lettenmaier, D. P. and Wood, E. F.: Hydrologic Forecasting, Chap. 26, in: Handbook of Hydrology, edited by: Maidment, D. R., McGraw-Hill, New York, USA. 1993.

Lindström, G., Johansson, B., Persson, M., Gardelin, M., and Bergström, S.: Development and test of the distributed HBV-96 hydrological model, J. Hydrol., 201, 272-288, 1997.

Nash, J. E. and Sutcliffe, J. V.: River flow forecasting through conceptual models (1), a discussion of principles. J. Hydrol., 10, 282-290, 1970.

O'Connell, P. E. and Clarke, R. T.: Adaptive hydrological forecasting - a review, Hydrol. Sci. Bull., 26(2), ISSN 0303-6936, 179205, 1981.

Refsgaard, J. C.: Validation and Intercomparison of Different Updating Procedures for Real-Time Forecasting, Nordic Hydrol., 28, ISSN 0029-1277, 65-84, 1997.

Sonderegger C.: Rainfall/Runoff Modelling of a Sub-Satchment of the Yangtze in China, Diploma Thesis at the ETH and University Zürich, 103 pages, 2004.

Uhlenbrook, S. and Leibundgut, C.: Process-oriented catchment modelling and multiple-response validation, Hydrol. Processes, 16, 423-440, 2002.

Verbunt, M., Zappa, M., Gurtz, J., and Kaufmann, P.: Verification of a coupled hydrometeorological modelling approach for alpine tributaries in the Rhine basin, J. Hydrol., 324, 224-238, doi:10.1016/j.jhydrol.2005.09.036, 2006.

WMO: Simulated real-time intercomparison of hydrological models, No. 779, World Meteorological Organization, ISBN 92-6310779-3, 1992.

Yang, X. and Michelle, C.: Flood forecasting with a watershed model: a new method of parameter updating, Hydrol. Sci., 45(4), 537-547, 2001.

Zappa, M.: Multiple-response verification of a distributed hydrological model at different spatial scales In Institute for Atmospheric and Climate Science, Dissertation No. 14895, ETH Zürich, 2003.

Zappa M. and Gurtz, J.: Simulation of soil moisture and evapotranspiration in a soil profile during the 1999 MAP-Riviera Cam- 
paign, Hydrol. Earth Syst. Sci., 7, 903-919, 2003,

http://www.hydrol-earth-syst-sci.net/7/903/2003/.

Zappa, M., Pos, F., Strasser, U., Warmerdam, P., and Gurtz. J.: Seasonal water balance of an Alpine catchment as evaluated by different methods for spatially distributed snowmelt modelling, Nordic Hydrol., 34, 179-202, 2003.
Zhang, X. N. and Lindstrom, G.: Development of an automatic calibration scheme for the HBV hydrological model, Hydrol. Processes, 11, 1671-1682, 1997. 